OPEN ACCESS

Edited by:

Jonathan Thornburg,

RTI International, United States

Reviewed by:

Sarah Petters,

University of North Carolina at Chapel

Hill, United States

Alex Kovach,

RTI International, United States

*Correspondence:

Michelle K. Page

michelle.page@roswellpark.org

Specialty section:

This article was submitted to

Analytical Chemistry,

a section of the journal

Frontiers in Chemistry

Received: 24 August 2021

Accepted: 11 October 2021

Published: 28 October 2021

Citation:

Page MK and Goniewicz ML (2021) New Analytical Method for Quantifying

Flavoring Chemicals of Potential Respiratory Health Risk Concerns in e-

Cigarette Liquids.

Front. Chem. 9:763940.

doi: 10.3389/fchem.2021.763940

\section{New Analytical Method for Quantifying Flavoring Chemicals of Potential Respiratory Health Risk Concerns in e-Cigarette Liquids}

\author{
Michelle K. Page * and Maciej L. Goniewicz \\ Department of Health Behavior, Roswell Park Comprehensive Cancer Center, Buffalo, NY, United States
}

Numerous flavoring chemicals are added to e-cigarette liquids to create various flavors. Flavorings provide sensory experience to users and increase product appeal; however, concerns have been raised about their potential inhalation toxicity. Estimating potential health risk of inhaling these chemicals has been challenging since little is known about their actual concentrations in e-cigarette products. To date, a limited number of analytical methods exist to measure the concentrations of flavoring chemicals in e-cigarette products. We have developed an analytical method that accurately and precisely measures the concentrations of 20 flavoring chemicals of potential inhalation risk concerns: 2,3,5-trimethylpyrazine, acetoin, benzaldehyde, benzyl alcohol, butanoic acid, dl-limonene, ethyl maltol, ethyl salicylate, ethyl vanillin, eucalyptol, eugenol, furaneol, isovanillin, I-menthol, maltol, methyl salicylate, pulegone, transcinnamaldehyde, triacetin, and vanillin. Calibration and QC solutions were prepared in 50:50 propylene glycol (PG):vegetable glycerin (VG) and 5\% $\mathrm{H}_{2} \mathrm{O}$ and flavoring concentrations ranging from 0.02 to $10.00 \mathrm{mg} / \mathrm{ml}$. Samples of commercial e-cigarette liquids, calibration and QC solutions were combined with $30 \mu \mathrm{L}$ of an internal standard mix (benzene-d6, pyridine-d5, chlorobenzene-d5, naphthalene-d8 and acenaphthene-d10; $1 \mathrm{mg} / \mathrm{ml}$ each) and were diluted 100-fold into methanol. Analysis was performed on an Agilent 7890B/7250 GC/Q-TOF using a DB-624UI column (30 m x 0.25 mmID x $1.4 \mu \mathrm{m}$ film thickness), with a total runtime of $13.5 \mathrm{~min}$. Calibration curves were fit using a weighted quadratic model and correlations of determination $\left(r^{2}\right)$ values exceeded 0.990 for all chemicals. Bias and precision tests yielded values less than $20 \%$ and lower limits of quantitation (LLOQ) ranged from 0.02 to $0.63 \mathrm{mg} / \mathrm{ml}$. Over 200 commercially available products, purchased or collected from adult e-cigarette users and spanning a range of flavor categories, were evaluated with this method. Concentrations of pulegone, a suspected carcinogen, varied from below limit of quantitation (BLOQ) to $0.32 \mathrm{mg} / \mathrm{ml}$, while acetoin and vanillin, known precursors to more cytotoxic byproducts, ranged from BLOQ to $1.52 \mathrm{mg} / \mathrm{ml}$ and from BLOQ to $16.22 \mathrm{mg} / \mathrm{ml}$, respectively. This method features a wide dynamic working range and allows for a rapid routine analysis of flavoring additives in commercial e-cigarette liquids.

Keywords: flavors, flavorings, flavoring chemicals, electronic cigarettes, e-cigarettes, E-liquids, E-cigarette refill solutions, vaping (Min 5-Max 8) 


\section{INTRODUCTION}

Flavoring chemicals are a main constituent of e-cigarette liquids and help impart either a characteristic flavor or contribute to the overall sensory experience of e-cigarette users (vapers). Over 7,000 e-cigarette liquid flavors are available to consumers (Zhu et al., 2014), with unlimited variations of added flavoring chemicals and their concentrations. The accessibility of flavors has led to higher likability of e-cigarette products (Kim et al., 2016) and higher initiation rates of vaping (Leventhal et al., 2019). As a result, an increase in preference and usage of flavored e-cigarettes has been shown among multiple population groups (Harrell et al., 2017), observed most strikingly among the youth population (Ambrose et al., 2015; Harrell et al., 2017). Users more frequently site flavors as their reason for initiation and usage (Pepper et al., 2016; Harrell et al., 2017; Russell et al., 2018) and the exposure from increased consumption of flavored liquids and their chemical flavorings, is worrisome from a public health perspective.

Previous qualitative methods have established the identities of the flavoring chemicals commonly used in tobacco products (Krüsemann et al., 2018), including e-cigarette liquids (Hutzler et al., 2014; Czoli et al., 2019). Among the most frequently reported flavorings in e-cigarette liquids, aldehydes (ethyl vanillin, vanillin, benzaldehyde and cinnamaldehyde), alcohols (l-menthol, benzyl alcohol and furaneol), esters (triacetin), ketones (ethyl maltol, maltol, acetoin) and terpenes (limonene, pulegone) are the most common (Hutzler et al., 2014; Tierney et al., 2016; Behar et al., 2018; Omaiye et al., 2019b; Czoli et al., 2019; Hua et al., 2019; Krüsemann et al., 2021). While considered "generally recognized as safe" (GRAS) for consumption, concerns have been raised about the potential inhalation toxicity associated with these chemicals. Initial findings suggest a link between inhalation toxicity of e-cigarettes and flavorings (Bahl et al., 2012; Leigh et al., 2016), while more recent in vitro studies have demonstrated specific chemicals such as cinnamaldehyde, benzaldehyde, ethyl vanillin, ethyl maltol and vanillin to be highly cytotoxic to respiratory cells (Behar et al., 2018; Hua et al., 2019; Rickard et al., 2021), as well as disruptive to normal cellular and immune function (Gerloff et al., 2017; Hickman et al., 2019). Selected flavoring chemicals have been also shown to form free radicals when heated in e-cigarette devices (Muthumalage et al., 2017; Bitzer et al., 2018), as well as known carcinogens such as benzene (Pankow et al., 2017), while others react with solvents used in e-cigarette liquids to form more highly cytotoxic acetal byproducts (Erythropel et al., 2019; Jabba et al., 2020). Further, ethyl vanillin and vanillin have been revealed to contain potentially addictive properties (Truman et al., 2019).

While exposure to flavoring chemical classes such as aldehydes and alcohols are more widely studied, the use of additional chemicals in e-cigarette liquids are also concerning. For example, pulegone is a suspected carcinogen at high concentrations and has subsequently been banned from food products in 2018 (Kidwell, 2018). Its presence in e-cigarette liquids; however, remains unregulated as the margin of exposure in some marketed e-cigarette liquids have been shown to far exceed that found in food (Jabba and Jordt,
2019). Further, acetoin is a known precursor to diacetyl formation in e-cigarette liquids (Vas et al., 2019), where diacetyl has been identified in a large number of sweet flavored liquids (Farsalinos et al., 2015). Importantly, occupational inhalation of diacetyl has previously demonstrated to cause serious human respiratory outcomes (bronchiolitis obliterans) (Kreiss et al., 2002). Similarly, the addition of triacetin to e-cigarette liquids has been correlated with increases in harmful smoke constituents, such as formaldehyde hemiacetals, acrolein and acetaldehyde (Vreeke et al., 2018), owing to the degradation of triacetin at high temperatures (Laino et al., 2012).

As research continues to focus on the health effects of flavoring chemicals used in flavored e-cigarette liquids, accurately estimating potential toxicity has been challenging since concentrations of these chemicals are generally not known. E-cigarette liquid manufacturers are not required to report chemical constituents or concentrations. Several studies have published concentrations of common flavoring chemical additives; however, validation of the methods used to determine accuracy of the reported results are limited. This study aimed to develop an accurate and highly efficient method, spanning a wide concentration range for the following 20 chemicals commonly found in e-cigarette liquids that are of potential inhalation concern: 2,3,5trimethylpyrazine, acetoin, benzaldehyde, benzyl alcohol, butanoic acid, dl-limonene, ethyl maltol, ethyl salicylate, ethyl vanillin, eucalyptol, eugenol, furaneol, isovanillin, l-menthol, maltol, methyl salicylate, pulegone, transcinnamaldehyde, triacetin and vanillin. Using this validated method, over 200 commercial e-cigarette liquids were assessed for concentrations of these 20 chemicals.

\section{MATERIALS AND METHODS}

\section{Chemicals}

Neat standards for the 20 flavoring chemicals and internal standards were purchased from Acros Organics (Fair Lawn, NJ), Alfa Aesar (Haverhill, MA), Cambridge Isotopes (Tewksbury, MA), Santa Cruz Biotechnology (Dallas, TX), Sigma Aldrich (St. Louis, MO), and TCI (Portland, OR) (Supplementary Table S1). The solvents methanol (LCMSgrade) and water (HPLC-grade) were obtained from Fisher Chemical (Waltham, MA), propylene glycol (PG) from Acros Organics and vegetable glycerin (VG) from Alfa Aesar.

\section{Preparation of Working Solutions}

A solvent solution of 50:50 (\%:\%) propylene glycol (PG) and vegetable glycerin (VG) was first prepared by combining $475 \mathrm{ml}$ of each along with $50 \mathrm{ml}$ of HPLC-grade water and mixing for 15 min using a magnetic stir plate (Fisher Scientific Isotemp ${ }^{\mathrm{TM}}$, Waltham, MA) at $350 \mathrm{rpm}$ and ambient temperature. The solution settled for $0.5 \mathrm{~h}$ to allow removal of trapped air bubbles from the mixing process. This solution was utilized for subsequent preparation of calibration, quality control and fortified matrix samples used in the validation of this method. 
Storage of the solution was in ambient dark conditions and prepared as needed.

A $20 \mathrm{mg} / \mathrm{ml}$ working solution containing the follow chemicals was prepared by weighing $2.0000 \pm 0.0005 \mathrm{~g}$ of each solid neat standard using a precision balance $(0.008-220 \mathrm{~g}$, Mettler-Toledo, Columbus, $\mathrm{OH}$ ) and dissolving into methanol: acetoin, ethyl maltol, ethyl vanillin, furaneol, isovanillin, maltol, l-menthol and vanillin. L-menthol was first crushed to a fine powder using a ceramic mortar and pestle. The mixture was handvortexed at 3,200 rpm using a vortex mixer (Fisher Scientific) for a minimum of $5 \mathrm{~min}$ or until all visible granules were dissolved. The working solution was stored in dark, $4^{\circ} \mathrm{C}$ conditions and prepared monthly.

A $1 \mathrm{mg} / \mathrm{ml}$ working internal standard (IS) solution was prepared into methanol, where $100 \mu \mathrm{L}$ of benzene-d6, chlorobenzene-d5 and pyridine-d5 and $100.0 \pm 0.05 \mathrm{mg}$ of naphthalene- $\mathrm{d} 8$ and acenapthene- $\mathrm{d} 10$ were measured and the solution hand-vortexed for a minimum of $5 \mathrm{~min}$. Internal standard solution was kept in ambient dark conditions and prepared yearly.

\section{Preparation of Working Calibration and Quality Control Standards}

Ten calibration and nine quality control (QC) concentrations were prepared ranging from 0.02 to $10.00 \mathrm{mg} / \mathrm{ml}$ and $0.03-8.00 \mathrm{mg} / \mathrm{ml}$, respectively by serial dilutions (2-fold) starting with the most concentrated level (Supplementary Table S2). Here, 100 and $80 \mu \mathrm{L}$ of each liquid neat standard (Supplementary Table S1) and $4 \mathrm{ml}$ of the $20 \mathrm{mg} / \mathrm{ml}$ working solution were gently mixed with 3.7 and $4.96 \mathrm{ml}$ of 50:50 PG:VG solution, respectively for $0.5 \mathrm{~h}$ using a vertical multi-function rotator (Grant Instruments, Shepreth, United Kingdom). Given the high concentration of the flavoring chemicals in the calibration standards as well as high concentrations expected in e-cigarette liquids, detector saturation with direct injection was of concern. To reduce this effect, each standard was diluted 100-fold prior to injection using similar methodology to dilute-and-shoot LCMS (Greer et al., 2021), by adding $30 \mu \mathrm{L}$ of each to $30 \mu \mathrm{L}$ of internal standard solution and $3 \mathrm{ml}$ of methanol. Calibration and QC standards were stored in $4{ }^{\circ} \mathrm{C}$ dark conditions and prepared monthly.

\section{Preparation of Fortified Matrix Samples for Method Validation}

Fortified matrix samples to validate the bias and precision of the method were prepared in triplicate at the following three concentrations within the instrument linear range: 1. approximately 3 times the lowest level, 2. middle of the range 3. within at least $70 \%$ of the highest level. Given the complexity of the ranges, this required the preparation of six fortified samples (at concentrations of $0.04,0.10,0.88,1.75,3.50$ and $7.00 \mathrm{mg} / \mathrm{ml}$ ). The most concentrated fortified sample was prepared first by adding each neat standard $(70 \mu \mathrm{L})$ and $20 \mathrm{mg} / \mathrm{ml}$ working standard $(3.5 \mathrm{ml})$ into the PG:VG solution $(5.59 \mathrm{ml})$ and gently mixing for $0.5 \mathrm{~h}$, followed by subsequent serial dilutions. To assess the lower limit of quantitation (LLOQ) for each chemical, additional fortified matrix samples were prepared at concentrations $0.5-2$ times the lowest level in the instrument linear range. This required the preparation of five samples (at concentrations of $0.01,0.04,0.07,0.10$ and $0.27 \mathrm{mg} / \mathrm{ml}$ ) and were prepared from individual dilutions of a working intermediate $(1 \mathrm{mg} / \mathrm{ml})$. Dilution capability of the method was evaluated by preparing independent fortified matrix samples at concentrations of 5 and $10 \mathrm{mg} / \mathrm{ml}$, using previously described procedures, and $18.6 \mathrm{mg} / \mathrm{ml}$, where solid and liquid neat standards were dissolved directly into 50:50 PG:VG. Similar to calibration and QC standards, all fortified matrix samples were diluted 100-fold with methanol and internal standard solution prior to analysis.

\section{Selection of Commercial E-Cigarette Liquids}

To test the capacity of the method, previously obtained e-cigarette liquids were selected for analysis based on the availability of popular flavors. Roughly half of the liquids were either purchased online or in vape shops (53\%), while the remainder $(47 \%)$ were collected from participants from observational studies of adult e-cigarette users. Most liquids were from the US (90\%), with several from Australia (7\%), the United Kingdom (3\%) and one liquid from Canada. This included 215 in total and incorporated 13 of 16 flavor categories from a recently published e-cigarette liquid flavor wheel (Krüsemann et al., 2019), increasing the probability of detecting the targeted flavorings chemicals of this method. Such flavor categories from the flavor wheel included Fruit (further delineated as tropical, berry, citrus and other), Dessert, Candy, and Menthol/Mint, in addition to Tobacco. E-cigarette liquids were stored in $4{ }^{\circ} \mathrm{C}$ dark conditions prior to analysis and were brought to room temperature and mixed for 1 hour using a vertical multifunction rotator. As with the calibration standards and fortified matrix samples, e-cigarette liquids were diluted 100fold with methanol and internal standard solution prior to analysis.

\section{Instrumental Analysis}

Sample analysis was performed on a 7890B/7250 GC/Q-TOF (Agilent Technologies, Santa Clara, CA), equipped with a PAL RSI 120 autosampler (CTC Analytics, Zwingen, Switzerland). Separation of chemicals was achieved using an Agilent DB-624UI (30 m x $0.25 \mathrm{mmID} \times 1.4 \mu \mathrm{m}$ film thickness) column. To ensure adequate settling of the stationary phase between injections and more reproducible retention times of early eluting chemicals, the column equilibrated for $2 \mathrm{~min}$ at initial conditions between injections. After pre-rinsing the needle with methanol, $1 \mu \mathrm{L}$ of the prepared aliquot was injected into $320^{\circ} \mathrm{C}$ with a split of $20: 1$. Initial oven conditions started at $60^{\circ} \mathrm{C}$ and were held for $1 \mathrm{~min}$. The temperature was then increased at a rate of $30^{\circ} \mathrm{C} / \mathrm{min}$ until reaching $225^{\circ} \mathrm{C}$ and held for an additional $4 \mathrm{~min}$. Postacquisition, the oven was ramped to $280^{\circ} \mathrm{C}$ and held for $1 \mathrm{~min}$ to help clean residual carryover. Total analysis time was $13.5 \mathrm{~min}$. Elution from the column into the mass spectrometer occurred at $250^{\circ} \mathrm{C}$ and source and quadrupole temperatures were held at $230^{\circ} \mathrm{C}$ and $150^{\circ} \mathrm{C}$, respectively. Positive ionization was performed 
using low-EI $(15 \mathrm{eV})$ with emission of $0.2 \mu \mathrm{A}$. Q/TOF scan range was between 50 and $250 \mathrm{amu}$, with acquisition rate and time of five spectra/sec and $200 \mathrm{~ms} / \mathrm{spectrum}$, respectively. Carrier flow (helium) was held constant at $2.0 \mathrm{ml} / \mathrm{min}$, while quench (helium) and collision (nitrogen) gases were held at $2.0 \mathrm{ml} / \mathrm{min}$ and $1.5 \mathrm{ml} /$ min, respectively. Needle rinses post-injection were first in acetone and followed by methanol.

Each acquisition batch consisted of up to 75 e-cigarette liquids, as well as one complete set of calibration $(0.02-10.00 \mathrm{mg} / \mathrm{ml})$ and QC $(0.03-8.00 \mathrm{mg} / \mathrm{ml})$ standards injected prior to the e-cigarette liquids and one complete set injected after. Using the responses from both sets of calibration standards, a calibration curve was plotted to measure the concentrations of chemicals identified in the e-cigarette liquids in the batch. Data review was performed using Agilent MassHunter software (Quantitation, v10.2) and automated method processing. Computer generated peak assignments and integrations were reviewed and corrected when applicable. Calibration curves were plotted for each chemical, using peak area and the internal standard method. Commercial liquids with chemicals exceeding the upper quantitation limit of the calibration curve range were diluted to a concentration near the middle of the calibration range ( $1 \mathrm{mg}$ / $\mathrm{ml}$ ). Dilutions of 2, 5 and 10X were performed with reduction of initial e-cigarette liquid volume, while dilutions of 20 and 50X also required adjusted final volumes of the solvent. To account for differing final volumes, the volume of the internal standard solution added was adjusted likewise to allow recovery within $\pm 20 \%$ compared to the calibration. Diluted liquids were reinjected with corresponding calibrators and QC.

\section{METHOD VALIDATION}

Validation of this method followed recommendations from the Scientific Working Group for Forensic Toxicology (SWGTOX) (Scientific Working Group for Forensic, 2013). To assess the suitability of internal standard concentration and assignments, relative response factors (RRF) across calibration standards for each chemical were calculated using the following equation:

$$
R R F=\frac{A_{s} \times C_{i s}}{A_{i s} \times C_{s}}
$$

Where:

$\mathrm{A}_{\mathrm{s}}=$ area response of the chemical.

$\mathrm{A}_{\mathrm{is}}=$ area response of the internal standard.

$\mathrm{C}_{\mathrm{s}}=$ concentration of the chemical.

$\mathrm{C}_{\mathrm{is}}=$ concentration of the internal standard.

Relative standard error (RSE) was calculated to determine the acceptability of the curve models, using the following equation:

$$
\% R S E=100 \times \sqrt{\sum_{i=1}^{n}\left[\frac{x_{i}^{\prime}-x_{i}}{x_{i}}\right]^{2}} /(n-p)
$$

Where:

$\mathrm{n}=$ number of calibration points

$\mathrm{x}_{i}=$ expected concentration of chemical in calibration level $i$ $\mathrm{x}_{i}{ }^{\prime}=$ measured concentration of chemical in calibration level $i$ $\mathrm{p}=$ number of term in the fitting equation (average $=1$,

linear $=2$, quadratic $=3$ ).

For all 20 chemicals, $\mathrm{p}=3$

Fortified matrix samples were analyzed in triplicate per batch, where seven batches in total were injected on separate days. Percent recovery of each calibrator, QC and fortified matrix sample were compared within batch (inter-day) and between batches (intra-day) and coefficient of variation $(\mathrm{CV})$ was used to determine precision and accuracy, where a range of $\pm 20 \%$ was considered acceptable (Scientific Working Group for Forensic, 2013). Precision was calculated using the following equation:

$$
\% C V=\frac{\text { Average Concentration }}{\text { Standard Deviation }} X 100
$$

Bias was determined using the following equation:

$\%$ Bias $=\frac{\text { Average Concentration }- \text { Expected Concentration }}{\text { Expected Concentration }} \times 100$

LLOQ values for the working calibration range were primarily determined from the lowest calibration level meeting $\pm 20 \%$ recovery and $\mathrm{CV}$, and secondly from the results of the LLOQ and carryover analyses. Carryover was assessed with three 50: 50 PG:VG and three methanol blank matrix samples following injection of the highest working standards ( 8 and $10 \mathrm{mg} / \mathrm{ml}$ ). Dilution capability was determined by targeting concentrations within the working calibration range with two- and 5-fold dilutions of each the 5,10 and $18.6 \mathrm{mg} / \mathrm{ml}$ fortified samples, while 10 - and 50 -fold dilutions were performed on the $10 \mathrm{mg} / \mathrm{ml}$ and $18.6 \mathrm{ml}$ samples only. Stability was assessed by percent recovery of several calibrators injected after 1 month against a newly prepared calibration.

\section{RESULTS}

\section{Chemical Identification}

Spectral identification and retention times (RTs) were established from independent analysis of each chemical (Table 1). The largest ion was selected for quantitation when possible and secondary ions were chosen at a minimum relative abundance of $10 \%$ of the quantitation ion, with exception of benzene-d6 (6.2\%). Five chemicals were further assigned tertiary ions meeting the minimum threshold. A $\mathrm{m} / \mathrm{z}$ window of $\pm 10 \mathrm{ppm}$ was applied to allow slight instrument measurement variations. The earliest eluting peak after internal standard benzene-d6 (2.722 min) was acetoin (3.382 $\mathrm{min}$ ) while the concluding peak isovanillin eluted at 8.747 min (Figure 1). PG and VG, while not included in the calibration, were observed at RTs of 3.759 and $5.599 \mathrm{~min}$, respectively. Several unknown peaks were observed at RTs of $5.892,6.431,6.929,7.603$ and $9.130 \mathrm{~min}$. Tentative identification by comparing spectral breakdown (with the most abundant ions of $121.0654,123.0810,121.0655,147.0810$ and $167.0709 \mathrm{~m} / \mathrm{z}$, respectively) to the National Institute of Standards and Technology (NIST) library suggest these may be benzaldehyde 
TABLE 1 | Retention time, Resolution, Quantitation and Qualitative lons and Internal Standard Assignments for Twenty Flavoring Chemicals.

\begin{tabular}{|c|c|c|c|c|c|c|c|c|c|c|c|}
\hline & \multirow[t]{2}{*}{ CAS } & \multirow{2}{*}{$\begin{array}{l}\text { Molecular } \\
\text { Formula }\end{array}$} & \multirow{2}{*}{$\begin{array}{c}\text { Molecular } \\
\text { Weight } \\
\text { (g/mol) }\end{array}$} & \multirow[t]{2}{*}{ RT (min) } & \multirow{2}{*}{$\begin{array}{l}\text { Peak } \\
\text { resolution }^{\mathrm{a}}\end{array}$} & \multicolumn{5}{|c|}{ m/z ( $\pm 10 p p m)$} & \multirow[t]{2}{*}{ IS Assignment } \\
\hline & & & & & & $1^{\circ}$ (Quant) & $2^{\circ}$ (Qual) & $\begin{array}{c}\text { Relative } \\
\text { abundance (\%) }\end{array}$ & $3^{\circ}$ (Qual) & $\begin{array}{c}\text { Relative } \\
\text { abundance (\%) }\end{array}$ & \\
\hline Acetoin & $513-86-0$ & $\mathrm{C} 4 \mathrm{H} 8 \mathrm{O} 2$ & 88.11 & 3.382 & 4.08 & 88.0530 & 73.0295 & 15.0 & --- & --- & Benzene-d6 \\
\hline Butanoic Acid & $107-92-6$ & $\mathrm{C} 4 \mathrm{H} 8 \mathrm{O} 2$ & 88.11 & 3.928 & 10.96 & 60.0211 & 73.0293 & 30.0 & --- & --- & Pyridine-d5 \\
\hline Benzaldehyde & $100-52-7$ & $\mathrm{C} 7 \mathrm{H} 6 \mathrm{O}$ & 106.12 & 5.141 & 2.35 & 106.0409 & 77.0395 & 84.0 & 105.0335 & 11.9 & Chlorobenzene-d5 \\
\hline \multicolumn{11}{|l|}{ Trimethylpyrazine } & Chlorobenzene-d5 \\
\hline D-Limonene & $5989-27-5$ & $\mathrm{C} 10 \mathrm{H} 16$ & 136.23 & 5.287 & 3.91 & 93.0705 & 121.1022 & 28.5 & 136.1257 & 33.5 & Chlorobenzene-d5 \\
\hline L-Limonene & 5989-54-8 & $\mathrm{C} 10 \mathrm{H} 16$ & 136.23 & 5.287 & 3.91 & 93.0705 & 121.1022 & 28.5 & 136.1257 & 33.5 & Chlorobenzene-d5 \\
\hline Eucalyptol & $470-82-6$ & $\mathrm{C} 10 \mathrm{H} 18 \mathrm{O}$ & 154.25 & 5.381 & 5.73 & 139.1129 & 154.1363 & 90.2 & --- & --- & Chlorobenzene-d5 \\
\hline Benzyl Alcohol & $100-51-6$ & $\mathrm{C} 7 \mathrm{H} 8 \mathrm{O}$ & 108.14 & 5.657 & 3.58 & 108.0566 & 79.0546 & 33.1 & 107.0498 & 62.0 & Chlorobenzene-d5 \\
\hline Furaneol & $3658-77-3$ & $\mathrm{C} 6 \mathrm{H} 8 \mathrm{O} 3$ & 128.13 & 5.738 & 17.42 & 128.0478 & 85.0294 & 38.9 & --- & --- & Chlorobenzene-d5 \\
\hline Maltol & $118-71-8$ & $\mathrm{C} 6 \mathrm{H} 6 \mathrm{O} 3$ & 126.11 & 6.132 & 8.74 & 126.0310 & 71.0136 & 15.2 & --- & --- & Chlorobenzene-d5 \\
\hline L-Menthol & $2216-51-5$ & $\mathrm{C} 1 \mathrm{OH} 20 \mathrm{O}$ & 156.26 & 6.334 & 6.31 & 123.1180 & 109.1024 & 37.7 & 138.1415 & 64.8 & Chlorobenzene-d5 \\
\hline Methyl Salicylate & $119-36-8$ & $\mathrm{C} 8 \mathrm{H} 8 \mathrm{O} 3$ & 152.15 & 6.489 & 4.52 & 120.0206 & 152.0469 & 79.1 & --- & --- & Naphthalene-d8 \\
\hline Ethyl Maltol & $4940-11-8$ & $\mathrm{C} 7 \mathrm{H} 8 \mathrm{O} 3$ & 140.14 & 6.597 & 6.75 & 140.0471 & 139.0399 & 32.1 & -.- & --- & Naphthalene-d8 \\
\hline (+)Pulegone & $89-82-7$ & $\mathrm{C} 1 \mathrm{OH} 16 \mathrm{O}$ & 152.23 & 6.752 & 5.51 & 81.0706 & 152.1203 & 87.2 & --- & --- & Naphthalene-d8 \\
\hline Ethyl Salicylate & $118-61-6$ & $\mathrm{C} 9 \mathrm{H} 10 \mathrm{O} 3$ & 166.17 & 6.887 & 2.02 & 120.0204 & 166.0624 & 64.4 & --- & --- & Naphthalene-d8 \\
\hline trans-Cinnamaldehyde & $104-55-2$ & $\mathrm{C} 9 \mathrm{H} 8 \mathrm{O}$ & 132.16 & 7.072 & 6.56 & 131.0499 & 132.0576 & 56.5 & --- & --- & Naphthalene-d8 \\
\hline Triacetin & $102-76-1$ & $\mathrm{C} 9 \mathrm{H} 14 \mathrm{O} 6$ & 218.20 & 7.230 & 8.86 & 103.0398 & 145.0506 & 62.8 & --- & --- & Naphthalene-d8 \\
\hline Eugenol & $97-53-0$ & $\mathrm{C} 10 \mathrm{H} 12 \mathrm{O} 2$ & 164.20 & 7.459 & 6.25 & 164.0830 & 149.0607 & 19.4 & --- & --- & Naphthalene-d8 \\
\hline Vanillin & $121-33-5$ & $\mathrm{C} 8 \mathrm{H} 8 \mathrm{O} 3$ & 152.15 & 8.130 & 14.91 & 152.0474 & 151.0399 & 55.4 & --- & --- & Naphthalene-d8 \\
\hline Ethyl Vanillin & $121-32-4$ & $\mathrm{C} 9 \mathrm{H} 10 \mathrm{O} 3$ & 166.17 & 8.571 & 0.33 & 137.0244 & 138.0321 & 66.6 & -.- & --- & Naphthalene-d8 \\
\hline Isovanillin & 621-59-0 & $\mathrm{C} 8 \mathrm{H} 8 \mathrm{O} 3$ & 152.50 & 8.747 & 11.91 & 152.0475 & 151.0400 & 59.4 & --- & --- & $\begin{array}{l}\text { Acenaphthene- } \\
\text { d10 }\end{array}$ \\
\hline \multicolumn{12}{|l|}{ Internal Standards (IS) } \\
\hline Benzene-d6 & $1076-43-3$ & $\mathrm{C} 6 \mathrm{H} 6$ & 84.15 & 2.722 & 27.66 & 84.0851 & 85.0886 & 6.2 & --- & --- & N/A \\
\hline Pyridine-d5 & $7291-22-7$ & C5H5N & 84.13 & 3.477 & 7.53 & 84.0739 & 56.0568 & 13.0 & --- & --- & N/A \\
\hline Chlorobenzene-d5 & $3114-55-4$ & $\mathrm{C} 6 \mathrm{H} 5 \mathrm{Cl}$ & 117.59 & 4.184 & 42.81 & 117.0396 & 119.0369 & 29.5 & -.- & --- & N/A \\
\hline Naphthalene-d8 & $1146-65-2$ & $\mathrm{C} 1 \mathrm{OH} 8$ & 136.22 & 6.478 & 0.58 & 136.1131 & 137.1168 & 10.1 & -.- & -.- & N/A \\
\hline Acenaphthene-d10 & $15067-26-2$ & $\mathrm{C} 12 \mathrm{H} 10$ & 164.27 & 8.585 & 5.40 & 164.1416 & 165.1449 & 11.8 & --- & --- & N/A \\
\hline
\end{tabular}

${ }^{a}$ Calculated using peak width $(W)$ (determined from full width at half maximum height (FWHM)) and retention time (RT) from the peak immediately following, using the equation $R_{s}=\left(R T_{2}-R T_{1}\right) / 0.5\left(W_{1}+W_{2}\right)$. 


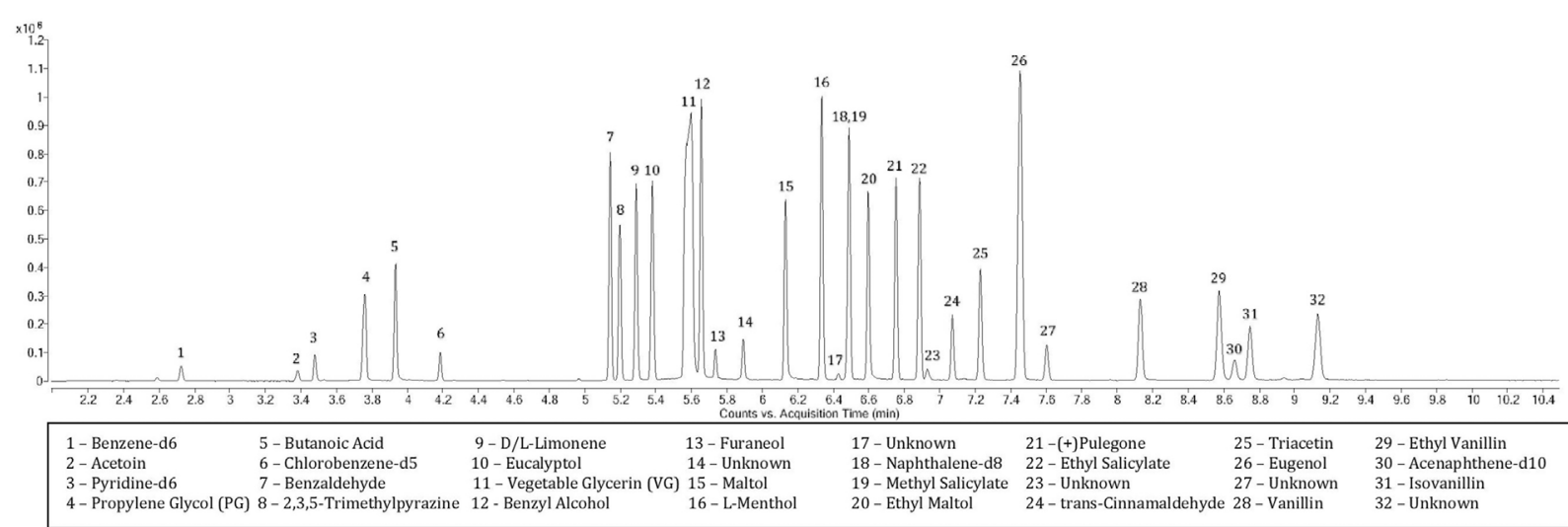

FIGURE 1 | Total lon Chromatogram of Targeted Flavoring Chemicals and Internal Standards.

dimethyl acetal (CAS\# 1125-88-8), isopulegone (CAS\# 29606-79-9), 2'-hydroxybutyrophenone (CAS\# 2887-61-8), cinnamaldehyde dimethyl acetal (CAS\# 4364-06-1) and 4-(2hydroxyethyl)-2,6-dimethoxyphenol (CAS\# 20824-4-7), respectively. Identities of these peaks were determined from the analysis of the total ion chromatogram (TIC) rather than through deconvolution processes, which could have revealed additional peaks at the specified retention times. Further, because the NIST was developed using nominal mass and an ionization energy of $70 \mathrm{eV}$, the spectral match to the data produced with high resolution (accurate) mass and low $\mathrm{eV}$ may not adequately identify these peaks. Peak resolution, calculated from the difference in retention times of the later and earlier eluting chemicals, divided by the average of the peak widths (Carle, 1972), was greater than 1.5 between each extracted ion current profile (EICP) with exception of ethyl vanillin and naphthalene-d8 (Table 1). Internal standard assignments are listed in Table 1.

\section{Calibration}

Coefficient of determination $\left(r^{2}\right)$ values measured among the seven batches consistently exceeded 0.990 for all chemicals when fit using a weighted quadratic $\left(1 / \mathrm{x}^{2}\right)$ model (Supplementary Table S3, Supplemental Figure S1). Average RRF ranged from 0.03 (acetoin) to 0.70 (2,3,5-trimethylpyrazine) and RSE averaged below $10 \%$ for each chemical. Instrument linearity was established over the entire final concentration range (after 100fold dilution) of 0.02 and $10 \mathrm{mg} / \mathrm{ml}$ for $20 \%$ of the chemicals. Benzyl alcohol, furaneol and trans-cinnamaldehyde reached detector saturation at a final concentration of $5 \mathrm{mg} / \mathrm{ml}$, while the remaining chemicals met linearity up to $10 \mathrm{mg} / \mathrm{ml}$ but had varying lower limits (Supplementary Table S3). The lowest values in the instrument linear range were determined from average percent recovery and bias (CV) across seven calibrations (Supplementary Table S4). Quality control levels within the established instrumental range recovered within $\pm 20 \%$ for each chemical. For $60 \%$ of the chemicals, the working calibration range met the same range as the instrument linear range. Butanoic acid, ethyl maltol, ethyl vanillin, isovanillin, maltol, trans-cinnamaldehyde, triacetin and vanillin each had tighter working calibration ranges (Supplementary Table S3), where additional lower levels were excluded based on results from the LLOQ and carryover method validation analyses.

\section{Method Validation}

Fortified matrix samples $(0.04,0.10,0.88,1.75,3.5$ and $7.0 \mathrm{mg} /$ $\mathrm{ml}$ ) showed high precision and low bias (within $\pm 20 \%$ ) when compared within and between batches for 95\% (19/20) of chemicals (Supplementary Table S5). Eucalyptol was within $\pm 30 \%$ among three batches, while intra-day precision and bias remained within $20 \%$. Greater variability was observed with recoveries of LLOQ fortified matrix samples $(0.01,0.04,0.07$, 0.10 and $0.27 \mathrm{mg} / \mathrm{ml}$ ) where nine chemicals exceeded $\pm 20 \%$ interand/or intra-batch precision (Supplementary Table S5). However, for seven of these chemicals, variability $( \pm 30 \%)$ was observed only in samples with concentrations below the instrumental linear range, where recoveries were considered estimated. Triacetin exceeded $30 \%$ inter- and intra-batch precision in 5/7 batches, resulting in a reduced working calibration range for this chemical. Bias across batches was within $\pm 20 \%$ for all chemicals except eugenol, where two LLOQ fortified matrix samples $(0.10$ and $0.27 \mathrm{mg} / \mathrm{ml})$ recovered within $\pm 30 \%$ of the true concentration. Carryover was observed for butanoic acid, ethyl maltol, ethyl vanillin, isovanillin, maltol and vanillin when PG:VG blanks were analyzed proceeding concentrated samples (Supplementary Table S6). Likewise, ethyl maltol, isovanillin, maltol, transcinnamaldehyde and vanillin demonstrated carryover in methanol blanks. Accordingly, LLOQ values in the working calibration range for these chemicals were raised so that carryover accounted for $<5 \%$ of the measured concentration. Dilutions of two- and 5-fold of each concentrated standard yielded intra-batch precision within $\pm 20 \%$ for each chemical (Supplementary Table S7), except for benzyl alcohol and furaneol. Likewise, 10 -fold dilutions of the 10 and $18.6 \mathrm{mg} / \mathrm{ml}$ samples were highly precise, with benzyl alcohol the sole chemical with higher variability between batches. Among the 50-fold dilutions, high precision was observed for $16 / 20$ chemicals. 


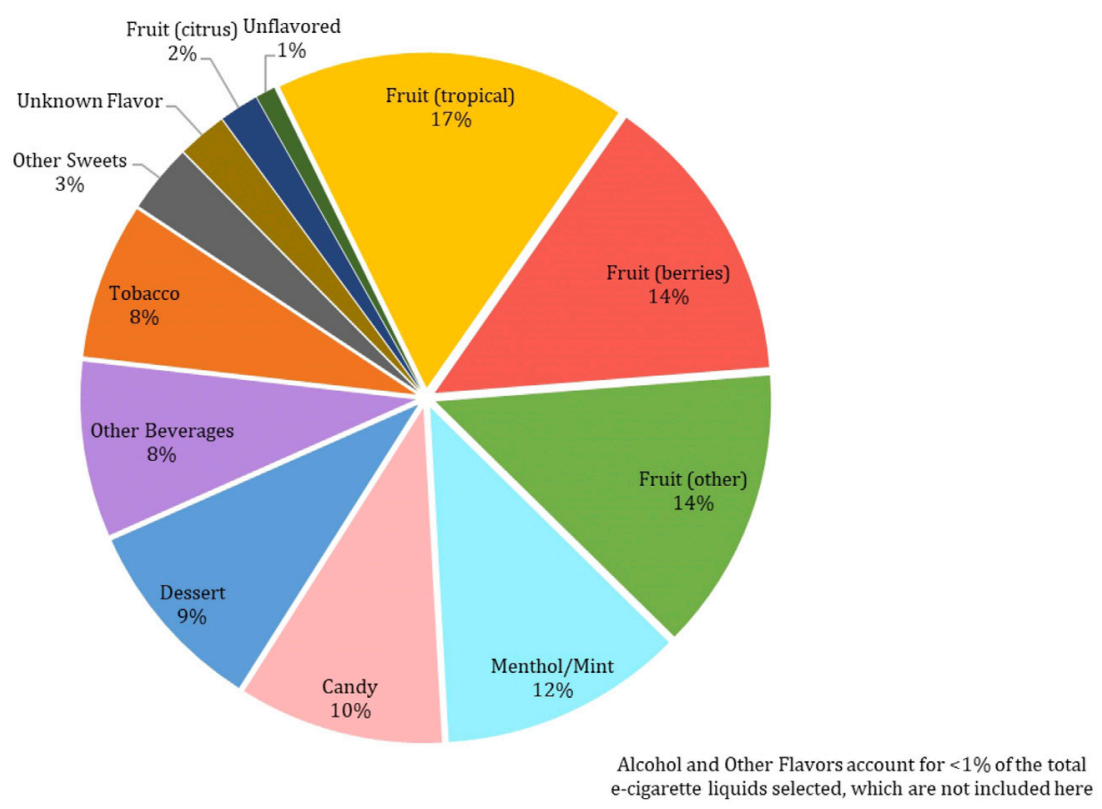

FIGURE 2 | Frequency of 215 Selected Commercial Flavored E-Cigarette Liquids by Flavor Category.

Bias among all dilutions was within $\pm 20 \%$ for $7 / 20$ chemicals, while $14 / 20$ were within $\pm 30 \%$. Stability over 1 month was observed in $18 / 20$ chemicals where recovery was within 80-120\%. Acetoin and furaneol presumably degraded, recovering below $80 \%$ of the expected concentration.

To assess the effect of the quadratic model on recovery, one acquisition batch was re-calculated after universally applying the linear $\left(1 / \mathrm{x}^{2}\right)$ model. Subsequent recovery of each calibration standard was then compared to the previously reported result. Sixteen chemicals had $r^{2}$ values exceeding 0.990 when fit using calibration standards within the working calibration range. Further, percent recoveries were within $\pm 20 \%$ of the expected concentration for each calibration and QC standard. Compared to the average recoveries reported in Supplementary Table S4, CV was within $\pm 20 \%$ for each standard of these 16 chemicals, with exception of the lowest calibration standard $(0.04 \mathrm{mg} / \mathrm{ml})$ for triacetin $(25 \% \mathrm{CV})$. DL-limonene, eucalyptol, furaneol and transcinnamaldehyde had calculated $r^{2}$ values of $0.853,0.985,0.981$ and 0.971 respectively, when calculated using a linear model. Concentrations of multiple standards when calculated against the linear fit were more variable, exceeding $\pm 30 \%$ recovery and CV compared to quadratic recoveries.

To determine the variation between calibration curves analyzed in the same acquisition batch, percent drift was calculated using the opening calibration as the reference. Here, concentration of each calibration standard in the second calibration was subtracted from the corresponding standard from the first calibration and divided by the concentration of the first standard. The resulting drift for each chemical across concentrations within their respective working calibration ranges were within $\pm 20 \%$ for all chemicals except dl-limonene ( $41 \%$ drift with $0.08 \mathrm{mg} / \mathrm{ml}$ standard), eucalyptol $(69,29$ and $27 \%$ drift for
$0.04,0.16$ and $0.31 \mathrm{mg} / \mathrm{ml}$ standards, respectively), benzyl alcohol (22\% drift for $0.02 \mathrm{mg} / \mathrm{ml}$ standard), l-menthol (22\% drift for $0.08 \mathrm{mg} / \mathrm{ml}$ standard) and pulegone $(28 \%$ drift for $0.02 \mathrm{mg} / \mathrm{ml}$ standard).

\section{Flavoring Chemicals in Commercial E-Cigarette Liquids}

Among the 215 e-cigarette liquids selected, fruit flavors were most predominately analyzed, with tropical, berry and other-flavors (such as watermelon) comprising of 17, 14 and 13\%, respectively of the total liquids (Figure 2). Between the remaining liquids, similar distributions across flavor categories were observed, where Menthol/Mint, Candy, Dessert, Other Beverages and Tobacco flavors encompassed 12, 10, 9, 8 and $8 \%$ of the liquids, respectively. All chemicals except for ethyl salicylate, isovanillin and trans-cinnamaldehyde were detected above the LLOQ in at least one e-cigarette liquid. Benzyl alcohol was the most abundant chemical found (in $41 \%$ of the products), followed by ethyl maltol (32\%) and triacetin (29\%) (Figure 3). L-menthol (detected in $21 \%$ of products) had the highest average concentration $(4.83 \mathrm{mg} / \mathrm{ml})$, followed by ethyl maltol $(3.84 \mathrm{mg} /$ $\mathrm{ml})$, vanillin $(3.81 \mathrm{mg} / \mathrm{ml})$, triacetin $(3.56 \mathrm{mg} / \mathrm{ml})$ and ethyl vanillin $(3.24 \mathrm{mg} / \mathrm{ml})$ (Figure 4$)$. Eight chemicals contained average concentrations below $1 \mathrm{mg} / \mathrm{ml}$ where 2,3,5trimethylpyrazine averaged the lowest among liquids with $0.10 \mathrm{mg} / \mathrm{ml}$. The highest individual concentrations were found with ethyl maltol $(32.49 \mathrm{mg} / \mathrm{ml}$, Candy-flavored), triacetin (23.15 mg/ml, Citrus fruit-flavored), ethyl vanillin $(19.07 \mathrm{mg} /$ $\mathrm{ml}$, Other Sweets-flavored) and 1 -menthol $(19.01 \mathrm{mg} / \mathrm{ml}$, Menthol/Mint-flavored) (Supplementary Table S8). The lowest concentrations identified were 2,3,5-trimethylpyrazine 


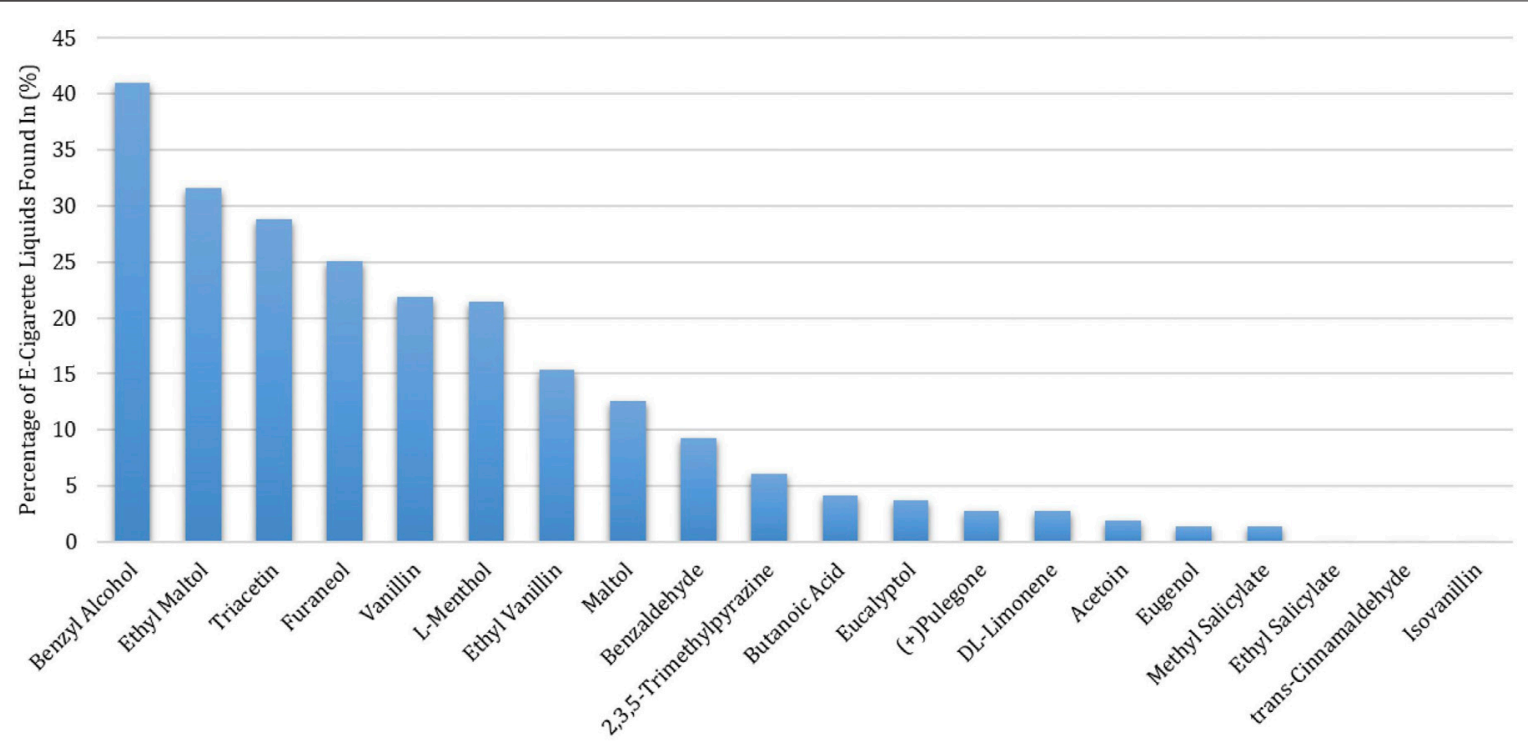

FIGURE 3 | Percentage of Detections of Twenty Flavoring Chemicals Found in 215 Commercial Flavored E-Cigarette Liquids.

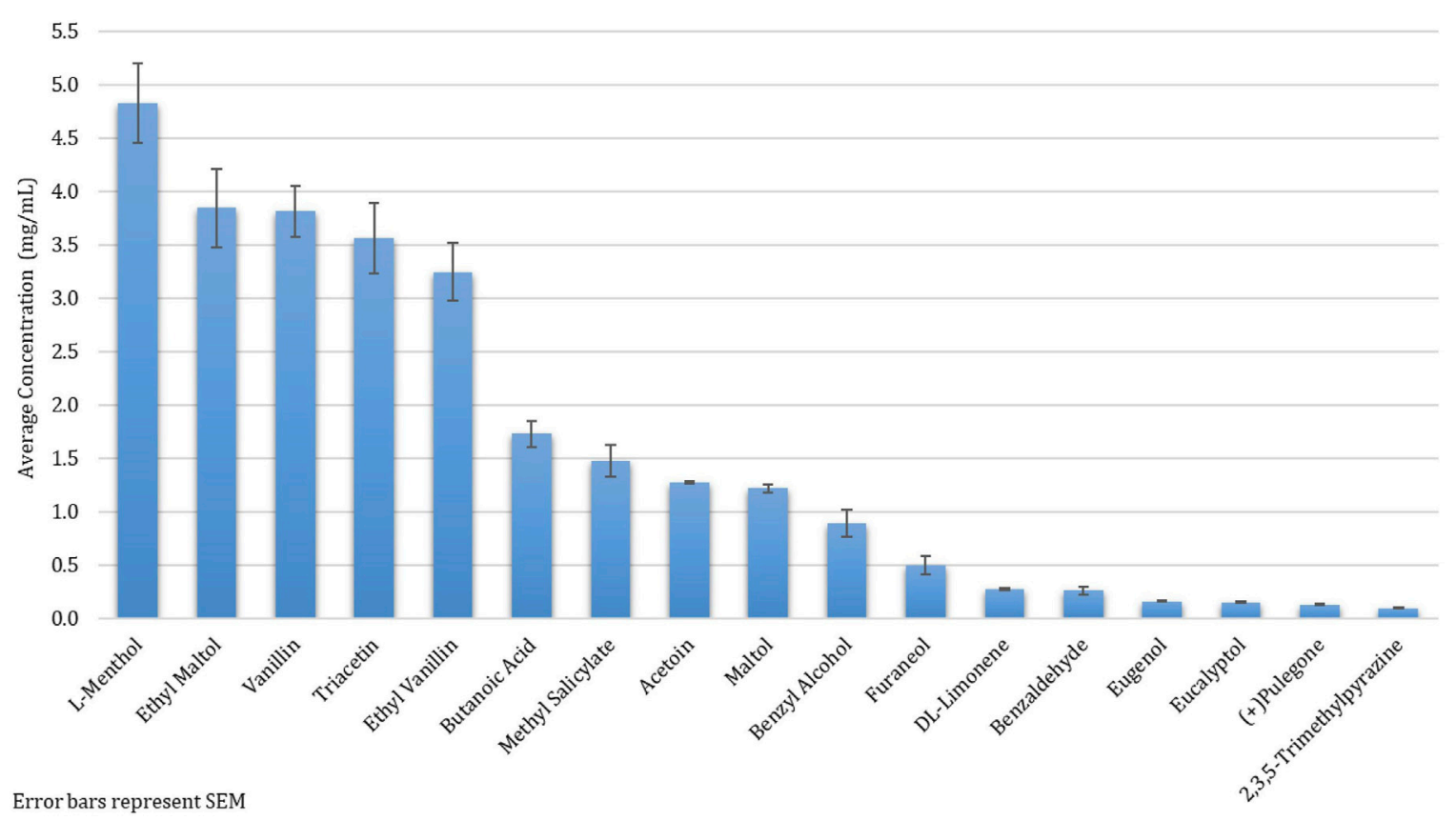

FIGURE 4 | Average Concentration of Twenty Flavoring Chemicals found in 215 Selected Commercial Flavored E-Cigarette Liquids.

and pulegone, where each were detected at $0.02 \mathrm{mg} / \mathrm{ml}$. Several chemicals were identified in at least half of the liquids assigned to a single flavor category and included eugenol $(100 \%$ in Fruit (tropical)), eucalyptol (100\% in Menthol/Mint), pulegone (83\% in Menthol/Mint), 2,3,5-trimethylpyrazine $(62 \%$ in Tobacco), acetoin (50\% in Dessert), and l-menthol (48\% in Menthol/Mint).

\section{DISCUSSION}

The validated method demonstrates repeatable and accurate measurement of 20 commonly added flavoring chemicals of potential inhalation concern, where precision and accuracy of flavoring chemicals across batches were consistently within $20 \%$. The large dynamic concentration range provides sensitivity for 
multiple chemicals in a single injection, while improving efficiency by reducing the frequency of re-analyses owing to overrange concentrations. As identified with this study, concentrations can vary by at least 1000 -fold. Nearly 500 detections were calculated and less than $5 \%$ of the measured e-cigarette liquids required subsequent dilution. Further, our results suggest benzyl alcohol, ethyl maltol, ethyl vanillin, l-menthol, triacetin and vanillin are more likely to be added to e-cigarette liquids in concentrations greater than $10 \mathrm{mg} / \mathrm{ml}$. This method has demonstrated precision and accuracy within $\pm 20 \%$ across multiple dilutions for these six chemicals, with exception of benzyl alcohol. Here, values greater than $20 \%$ are found predominately with dilutions of the $10 \mathrm{mg} / \mathrm{ml}$ sample, suggesting a preparation issue with this chemical.

Quadratic calibration models were selected for several chemicals, rather than using a curve splitting technique for wide calibration concentration ranges (Basu et al., 2012) resulting in expediting data review. This model was universally applied throughout the method validation process to all chemicals for consistency. Calibration curves for many chemicals, however; were observed to follow linear trajectories (Supplemental Figure S1). To understand the difference in curve models, re-calculation of data in a single acquisition batch was performed using linear calibration curves for each chemical. After comparison to previous quadratic-fit data, concentrations of most chemicals $(16 / 20)$ did not vary substantially, indicating minimal bias with the use of the quadratic model. Future assessment of the method should include the use of linear models for these chemicals. Recoveries of dl-limonene, eucalyptol, furaneol and trans-cinnamaldehyde varied more substantially after applying a linear model (without the use of curve splitting techniques), indicating a clear difference in instrumental response and suggestive of potential bias in the reported quadratic-based concentrations. However, recoveries from the fortified matrix samples at concentrations spanning the working calibration range were within $\pm 20 \%$ of expected concentrations. Based on this validation, minimal bias is assumed with the quadratic model.

Benzyl alcohol, which had a reduced upper limit of quantitation, was relatively linear across validation batches. Two out of the seven acquisition batches used in the method validation experienced detector saturation beyond a final concentration of $5 \mathrm{mg} / \mathrm{ml}$, for unknown reasons. Recoveries of benzyl alcohol from these batches were not excluded, leading to higher variability when assessing precision and bias. Based on these results, the upper level of quantitation (ULOQ) was lowered to $5 \mathrm{mg} / \mathrm{ml}$. Subsequent analyses using this method has continued to show linearity beyond $5 \mathrm{mg} / \mathrm{ml}$ and method validation should be repeated for this chemical to establish high precision and low bias at a final concentration of $10 \mathrm{mg} / \mathrm{ml}$.

Minimal carryover in methanol-only and PG/VG-only blanks injected immediately following the highest calibration standard was observed for six chemicals. Butanoic acid and ethyl vanillin appeared in PG/VG blanks only, suggesting that methanol alone, if used to assess carryover, is not sufficient to remove these chemicals from the system. Since e-cigarette liquids contain $\mathrm{PG} / \mathrm{VG}$, high concentrations of these chemicals may cause biased results in the subsequent injection. This has not been reported in previously published studies. To reduce this effect, LLOQ values were elevated such that reported concentrations were greater than $5 \%$ of possible carryover. Increased LLOQ values reduces the sensitivity of the method; however, several of these chemicals (ethyl maltol, ethyl vanillin and vanillin) were frequently found in higher concentrations, or not detected (isovanillin and trans-cinnamaldehyde) and are therefore not likely affected.

Multiple internal standards were included so that elution would span the chromatographic run and allow better representation of similarly eluting target chemicals. Relative retention times (RRT) of flavoring chemicals compared to their assigned internal standard were within the EPA suggested range of $0.80-1.20$ (EPA, 2014) for $50 \%$ of the chemicals, while the furthest chemical was 1.51 (l-menthol) relative to its internal standard. Relative response factors (RRF) were calculated to assess the suitability of these assignments and selected concentration. Internal standard response should fall below 100 times the response of the target chemical, corresponding to a minimum value of 0.01 and an ideal value of 1 (EPA, 2014). Our method exceeds the minimum value for all chemicals, the lowest reaching 0.03 (acetoin). Validation batches exhibited consistent RRF values (data not shown), which further demonstrates the repeatability and stability of the instrument response over time.

The analytical column used in this method (DB-624 UI) was selected for the stationary phase, which is considered of intermediate polarity (Sigma-Aldrich, 2013) and designed for the rapid separation of volatile chemicals (Agilent_Products, 2021). Ultra Inert (UI) provides improved bonding and crosslinking of the stationary phase, leading to less column bleed and a lower baseline signal. Dimensions were selected to improve the efficiency of separations, which included a column length of $30 \mathrm{~m}$ and internal diameter of $0.25 \mathrm{~mm}$ (Rahman et al., 2015). Given the high concentrations of flavoring chemicals expected in e-cigarette liquids, a relatively large film thickness $(1.4 \mu \mathrm{m})$ was selected to allow maximal loading capacity. Increased film thickness tends to increase peak width as chemical species are retained longer on the column, leading to reduced resolution, however; the chromatography observed in our method did not suffer.

This method takes advantage of innovative low-EI technology available in GC coupled MS instrumentation. Having a reduced applied ionization voltage $(15 \mathrm{eV}$ versus the traditional $70 \mathrm{eV})$ lowers the energy delivered to subsequent collisions of electrons with incoming chemical species and reduces the efficiency of ionization (Lau et al., 2019). This provides a two-fold advantage. First, given the high expected abundance of most flavoring chemicals in e-cigarette liquids, fewer chemical species are ionized, reducing potential detector saturation. Secondly, given the relatively small mass of the targeted flavoring chemicals, lower voltages may lead to softer fragmentation and increased abundance of the molecular ion. A comparison between ionization energies to understand fragmentation patterns of the flavoring chemicals was not performed in this study.

Detector sensitivity to matrix interference was not a concern in this method. The 7250 GC/Q-TOF, the newest of Q-TOF 
instrumentation from Agilent (currently), improves on the detector sensitivity of previous generations and has been utilized in low level detections of environmental contaminants. Here, the instrument has been shown to detect concentrations less than $10 \mathrm{ppb}$, while demonstrating sufficient separation from background noise (Agilent_Promotions, 2021). In contrast, the lowest detectable concentration required by our method is 2000 fold higher (20,000 ppb).

Few quantitative methods are available to measure concentrations of popular flavor additives in e-cigarette liquids, mainly using GC-MS (Bansal et al., 2019). Several studies followed a developed method containing 90 chemicals (Tierney et al., 2016) which was later expanded to 178 (Behar et al., 2018; Omaiye et al., 2019a; Omaiye et al., 2019b; Hua et al., 2019). Authentication standards were used to establish identifications; however, each study references the same published method for calibration procedures (Brown et al., 2014), where neither calibration or method validation information was provided. Further, this method was developed to measure chemicals in tobacco products and did not evaluate the e-cigarette liquid matrix. Likewise, an early published method used authentication standards to verify detections; however, only a three-point calibration was prepared (Schober et al., 2014) where concentrations were not reported. The wide range of concentrations found in their e-cigarette liquids combined with the lack of validation results yields uncertainty in the accuracy of the method. Conversely, the method published by Aszyk et al. includes a comprehensive method validation, offering bias and precision information for 46 chemicals, but excludes key flavoring chemicals with inhalation concern, such as ethyl maltol, ethyl vanillin, l-menthol, and vanillin (Aszyk et al., 2017). Important method parameters such as a reduced calibration range and use of acetonitrile limits time and cost effectiveness, which our method improves upon. Krüsemann et al. published a study which evaluated the validity of their method, but similarly had a limited calibration range (10-fold) and reduced target list (10 flavoring chemicals) (Krüsemann et al., 2020). In each of these published methods, the calibration curves have been prepared in the same organic solvent used to dilute the liquid. Our method is the first to prepare calibration levels using a similar matrix as the e-cigarette liquids themselves. Aszyk et al. evaluated matrix effects that impact the reported concentrations as part of their method validation. Our method accounts for this, therefore providing more accurate values for several chemicals identified with high matrix effects, such as benzyl alcohol (34\%) and eugenol (133\%) (Aszyk et al., 2017).

Our results confirm previous findings that high concentrations of several concerning flavoring chemicals are found in e-cigarette liquids (ethyl maltol, ethyl vanillin, triacetin, and vanillin). Further, pulegone was found almost exclusively in menthol/ mint-flavored liquids at concentrations ranging from 0.02 to $0.32 \mathrm{mg} / \mathrm{ml}$. Cinnamaldehyde, demonstrated to be highly cytotoxic (Behar et al., 2016) and disruptive to the immune response (Clapp et al., 2017), was not detected in any liquid tested in our study. This is not surprising since e-cigarette liquids with this characterizing cinnamon flavor were not included here. Our lower quantitation limits, however; allows for surveillance of such chemicals that may be added without the purpose of characterizing taste. For example, eugenol, with a flavor descriptor of spicy clove (The_Good_Scents_Company, 1980) is a common flavoring chemical found in clove cigarettes (Stanfill et al., 2006). While clove-flavored e-cigarette liquids were not included, this chemical was measured in low concentrations $(<1 \mathrm{mg} / \mathrm{ml})$ among several liquids exclusively characterized as tropical fruit-flavored. This is concerning as eugenol in clove cigarettes has been associated with pulmonary edema (LaVoie et al., 1986; Mcdonald and Heffner, 1991) and further acts as an anesthetic (Guidotti et al., 1989), allowing for deeper inhalation and more severe lung effects (infection and respiratory damage) (Hendee, 1988). Presence of this chemical in e-cigarette liquids, particularly in highly popular fruit flavors (Nguyen et al., 2019), may create a similar anesthetic effect, to which we have not identified published research relevant to e-cigarette users.

\section{Limitations}

The stability of stock standards was not verified with newly purchased standards. Although storage followed vendor recommendations between use, the shelf-life of opened standards is generally unknown. This is particularly true of furaneol, where reactions with oxygen are visually observed with physical changes over time, despite storage under inert gas. Stability tests of calibration standards further demonstrates this loss, with less than $80 \%$ recovery after 1 month. Known degradation of acetoin was also observed after 1 month in calibration standards; however, the conversion to diacetyl was not assessed. Additionally, conversion of several aldehydes to their acetal forms was not determined with this method; however, acetals were observed qualitatively throughout the method validation process. Given the stability of the aldehydes in calibration solutions over 1 month, the conversion to acetals may be relatively quick as previously demonstrated (Erythropel et al., 2019). Reduced initial concentrations could lead to high biased measurements in e-cigarette liquids. Similarly, the e-cigarette liquids included here were previously obtained and degradation of flavoring chemicals are possible. Stability assessments of these 20 chemicals in commercial e-cigarette liquids is an ongoing project. Finally, the impact of PG/VG ratio in each calibration level is unknown. Since the initial level was prepared with nearly 50:50 methanol:PG/VG and increasing PG/VG volume for subsequent levels, the density differs between calibrators. However, linearity was established for all chemicals and multiple validation samples prepared with differing methanol to $\mathrm{PG} / \mathrm{VG}$ ratios did not indicate substantial differences in recovery.

\section{CONCLUSION}

Our newly developed method allows for the precise and accurate measurement of a wide range of concentrations for twenty flavoring chemicals of inhalation concern in commercial flavored e-cigarette liquids. With greater accuracy in the measurement among the liquid, the percentage of conversion to the aerosol and subsequent inhalation by the user can further 
assessed. This method can be applied to an assessment of inhalation exposure to flavoring chemicals in e-cigarette users.

\section{DATA AVAILABILITY STATEMENT}

The raw data supporting the conclusions of this article will be made available by the authors, without undue reservation.

\section{AUTHOR CONTRIBUTIONS}

The methodology and design of this project was developed by MG, who also oversaw its completion. The work was performed, and manuscript drafted by MP. Review and edits of the manuscript were done by both authors.

\section{REFERENCES}

Agilent_Products (2021). Agilent_Products DB-624 Ultra Inert Columns. Available: https://www.agilent.com/en/product/gc-columns/ultra-inert-gccolumns/db-624-ultra-inert-columns (Accessed September 22, 2021).

Agilent_Promotions (2021). Agilent_Promotions Agilent 7250 GC/Q-TOF System. See the Whole Picture. Available: https://www.agilent.com/en/ promotions/7250-gc-q-tof (Accessed September 22, 2021).

Ambrose, B. K., Day, H. R., Rostron, B., Conway, K. P., Borek, N., Hyland, A., et al. (2015). Flavored Tobacco Product Use Among US Youth Aged 12-17 Years, 2013-2014. JAMA 314 (17), 1871-1873. doi:10.1001/jama.2015.13802

Aszyk, J., Woźniak, M. K., Kubica, P., Kot-Wasik, A., Namieśnik, J., and Wasik, A. (2017). Comprehensive Determination of Flavouring Additives and Nicotine in E-Cigarette Refill Solutions. Part II: Gas-Chromatography-Mass Spectrometry Analysis. J. Chromatogr. A 1517, 156-164. doi:10.1016/j.chroma.2017.08.057

Bahl, V., Lin, S., Xu, N., Davis, B., Wang, Y.-h., and Talbot, P. (2012). Comparison of Electronic Cigarette Refill Fluid Cytotoxicity Using Embryonic and Adult Models. Reprod. Toxicol. 34 (4), 529-537. doi:10.1016/j.reprotox.2012.08.001

Bansal, V., Hashemi, B., Raza, N., Kim, K.-H., Raza, W., Kumar, P., et al. (2019). Review of the Analytical Methods for and Clinical Impact of Additives and Flavors Used in Electronic Cigarettes. Expo. Health 12 (4), 593-615. doi:10.1007/s12403-019-00331-x

Basu, S., Basit, A., Ravindran, S., Patel, V. B., Vangala, S., and Patel, H. (2012). Split Calibration Curve: an Approach to Avoid Repeat Analysis of the Samples Exceeding ULOQ. Bioanalysis 4 (19), 2375-2389. doi:10.4155/bio.12.219

Behar, R. Z., Luo, W., Lin, S. C., Wang, Y., Valle, J., Pankow, J. F., et al. (2016). Distribution, Quantification and Toxicity of Cinnamaldehyde in Electronic Cigarette Refill Fluids and Aerosols. Tob. Control. 25 (Suppl. 2), ii94-ii102. doi:10.1136/tobaccocontrol-2016-053224

Behar, R. Z., Luo, W., McWhirter, K. J., Pankow, J. F., and Talbot, P. (2018). Analytical and Toxicological Evaluation of Flavor Chemicals in Electronic Cigarette Refill Fluids. Sci. Rep. 8 (1), 8288. doi:10.1038/s41598-018-25575-6

Bitzer, Z. T., Goel, R., Reilly, S. M., Elias, R. J., Silakov, A., Foulds, J., et al. (2018). Effect of Flavoring Chemicals on Free Radical Formation in Electronic Cigarette Aerosols. Free Radic. Biol. Med. 120, 72-79. doi:10.1016/ j.freeradbiomed.2018.03.020

Brown, J. E., Luo, W., Isabelle, L. M., and Pankow, J. F. (2014). Candy Flavorings in Tobacco. N. Engl. J. Med. 370 (23), 2250-2252. doi:10.1056/NEJMc1403015

Carle, G. C. (1972). Determination of Chromatographic Resolution for Peaks of Vast Concentration Differences. Anal. Chem. 44 (11), 1905-1906. doi:10.1021/ ac60319a030

Clapp, P. W., Pawlak, E. A., Lackey, J. T., Keating, J. E., Reeber, S. L., Glish, G. L., et al. (2017). Flavored E-Cigarette Liquids and Cinnamaldehyde Impair Respiratory Innate Immune Cell Function. Am. J. Physiology-Lung Cell Mol. Physiol. 313 (2), L278-L292. doi:10.1152/ajplung.00452.2016

\section{FUNDING}

Research reported here was supported by the National Cancer Institute of the National Institutes of Health (NIH) and the Food and Drug Administration (FDA) Center for Tobacco Products under Award Number U54CA228110. The content is solely the responsibility of the authors and does not necessarily represent the official views of the NIH or the FDA.

\section{SUPPLEMENTARY MATERIAL}

The Supplementary Material for this article can be found online at: https://www.frontiersin.org/articles/10.3389/fchem.2021.763940/ full\#supplementary-material

Czoli, C. D., Goniewicz, M. L., Palumbo, M., Leigh, N., White, C. M., and Hammond, D. (2019). Identification of Flavouring Chemicals and Potential Toxicants in E-Cigarette Products in Ontario, Canada. Can. J. Public Health 110 (5), 542-550. doi:10.17269/s41997-019-00208-1

EPA (2014). SW-846 Test Method 8000D: Determinative Chromatographic Separations. Washington, DC): US EPA.

Erythropel, H. C., Jabba, S. V., DeWinter, T. M., Mendizabal, M., Anastas, P. T., Jordt, S. E., et al. (2019). Formation of Flavorant-Propylene Glycol Adducts with Novel Toxicological Properties in Chemically Unstable E-Cigarette Liquids. Nicotine Tob. Res. 21 (9), 1248-1258. doi:10.1093/ntr/nty192

Farsalinos, K. E., Kistler, K. A., Gillman, G., and Voudris, V. (2015). Evaluation of Electronic Cigarette Liquids and Aerosol for the Presence of Selected Inhalation Toxins. Nicotine Tob. Res. 17 (2), 168-174. doi:10.1093/ntr/ntu176

Gerloff, J., Sundar, I. K., Freter, R., Sekera, E. R., Friedman, A. E., Robinson, R., et al. (2017). Inflammatory Response and Barrier Dysfunction by Different E-Cigarette Flavoring Chemicals Identified by Gas Chromatography-Mass Spectrometry in E-Liquids and E-Vapors on Human Lung Epithelial Cells and Fibroblasts. Appl. Vitro Toxicol. 3 (1), 28-40. doi:10.1089/aivt.2016.0030

Greer, B., Chevallier, O., Quinn, B., Botana, L. M., and Elliott, C. T. (2021). Redefining Dilute and Shoot: The Evolution of the Technique and its Application in the Analysis of Foods and Biological Matrices by Liquid Chromatography Mass Spectrometry. Trac Trends Anal. Chem. 141, 116284 doi:10.1016/j.trac.2021.116284

Guidotti, T. L., Laing, L., and Prakash, U. B. (1989). Clove Cigarettes. The Basis for Concern Regarding Health Effects. West. J. Med. 151 (2), 220-228.

Harrell, M. B., Weaver, S. R., Loukas, A., Creamer, M., Marti, C. N., Jackson, C. D., et al. (2017). Flavored E-Cigarette Use: Characterizing Youth, Young Adult, and Adult Users. Prev. Med. Rep. 5, 33-40. doi:10.1016/j.pmedr.2016.11.001

Hendee, W. (1988). Evaluation of the Health hazard of Clove Cigarettes. JAMA 260, 3641. doi:10.1001/jama.1988.03410240111042

Hickman, E., Herrera, C. A., and Jaspers, I. (2019). Common E-Cigarette Flavoring Chemicals Impair Neutrophil Phagocytosis and Oxidative Burst. Chem. Res. Toxicol. 32 (6), 982-985. doi:10.1021/acs.chemrestox.9b00171

Hua, M., Omaiye, E. E., Luo, W., McWhirter, K. J., Pankow, J. F., and Talbot, P. (2019). Identification of Cytotoxic Flavor Chemicals in Top-Selling Electronic Cigarette Refill Fluids. Sci. Rep. 9 (1), 2782. doi:10.1038/s41598-019-38978-w

Hutzler, C., Paschke, M., Kruschinski, S., Henkler, F., Hahn, J., and Luch, A. (2014). Chemical Hazards Present in Liquids and Vapors of Electronic Cigarettes. Arch. Toxicol. 88 (7), 1295-1308. doi:10.1007/s00204-014-1294-7

Jabba, S. V., Diaz, A. N., Erythropel, H. C., Zimmerman, J. B., and Jordt, S.-E. (2020). Chemical Adducts of Reactive Flavor Aldehydes Formed in E-Cigarette Liquids Are Cytotoxic and Inhibit Mitochondrial Function in Respiratory Epithelial Cells. Nicotine Tob. Res. 22 (Suppl. 1), S25-S34. doi:10.1093/ntr/ ntaal 185

Jabba, S. V., and Jordt, S.-E. (2019). Risk Analysis for the Carcinogen Pulegone in Mint- and Menthol-Flavored E-Cigarettes and Smokeless Tobacco Products. 
JAMA Intern. Med. 179 (12), 1721-1723. doi:10.1001/ jamainternmed.2019.3649

Kidwell, J. (2018). Synthetic Flavoring Agents and Adjuvants. FDA. Food Additive Regul. ed 83, 50490-50503.

Kim, H., Lim, J., Buehler, S. S., Brinkman, M. C., Johnson, N. M., Wilson, L., et al. (2016). Role of Sweet and Other Flavours in Liking and Disliking of Electronic Cigarettes. Tob. Control. 25 (Suppl. 2), ii55-ii61. doi:10.1136/tobaccocontrol2016-053221

Kreiss, K., Gomaa, A., Kullman, G., Fedan, K., Simoes, E. J., and Enright, P. L. (2002). Clinical Bronchiolitis Obliterans in Workers at a Microwave-Popcorn Plant. N. Engl. J. Med. 347 (5), 330-338. doi:10.1056/nejmoa020300

Krüsemann, E. J., Visser, W. F., Cremers, J. W., Pennings, J. L., and Talhout, R. (2018). Identification of Flavour Additives in Tobacco Products to Develop a Flavour Library. Tob. Control. 27 (1), 105-111. doi:10.1136/tobaccocontrol2016-052961

Krüsemann, E. J. Z., Boesveldt, S., de Graaf, K., and Talhout, R. (2019). An E-Liquid Flavor Wheel: A Shared Vocabulary Based on Systematically Reviewing E-Liquid Flavor Classifications in Literature. Nicotine Tob. Res. 21 (10), 1310-1319. doi:10.1093/ntr/nty101

Krüsemann, E. J. Z., Havermans, A., Pennings, J. L. A., de Graaf, K., Boesveldt, S., and Talhout, R. (2021). Comprehensive Overview of Common E-Liquid Ingredients and How They Can Be Used to Predict an E-Liquid's Flavour Category. Tob. Control. 30 (2), 185-191. doi:10.1136/tobaccocontrol-2019-055447

Krüsemann, E. J. Z., Pennings, J. L. A., Cremers, J. W. J. M., Bakker, F., Boesveldt, S., and Talhout, R. (2020). GC-MS Analysis of E-Cigarette Refill Solutions: A Comparison of Flavoring Composition between Flavor Categories. J. Pharm. Biomed. Anal. 188, 113364. doi:10.1016/j.jpba.2020.113364

Laino, T., Tuma, C., Moor, P., Martin, E., Stolz, S., and Curioni, A. (2012). Mechanisms of Propylene Glycol and Triacetin Pyrolysis. J. Phys. Chem. A. 116 (18), 4602-4609. doi:10.1021/jp300997d

Lau, H., Liu, S. Q., Tan, L. P., Lassabliere, B., Sun, J., and Yu, B. (2019). A Systematic Study of Molecular Ion Intensity and Mass Accuracy in Low Energy Electron Ionisation Using Gas Chromatography-Quadrupole Time-Of-Flight Mass Spectrometry. Talanta 199, 431-441. doi:10.1016/j.talanta.2019.02.089

LaVoie, E. J., Adams, J. D., Reinhardt, J., Rivenson, A., and Hoffmann, D. (1986). Toxicity Studies on Clove Cigarette Smoke and Constituents of Clove: Determination of the LD50 of Eugenol by Intratracheal Instillation in Rats and Hamsters. Arch. Toxicol. 59 (2), 78-81. doi:10.1007/bf00286727

Leigh, N. J., Lawton, R. I., Hershberger, P. A., and Goniewicz, M. L. (2016). Flavourings Significantly Affect Inhalation Toxicity of Aerosol Generated from Electronic Nicotine Delivery Systems (ENDS). Tob. Control. 25 (Suppl. 2), ii81-ii87. doi:10.1136/tobaccocontrol-2016-053205

Leventhal, A. M., Goldenson, N. I., Barrington-Trimis, J. L., Pang, R. D., and Kirkpatrick, M. G. (2019). Effects of Non-tobacco Flavors and Nicotine on E-Cigarette Product Appeal Among Young Adult Never, Former, and Current Smokers. Drug and Alcohol Dependence 203, 99-106. doi:10.1016/ j.drugalcdep.2019.05.020

Mcdonald, J. W., and Heffner, J. E. (1991). Eugenol Causes Oxidant-Mediated Edema in Isolated Perfused Rabbit Lungs. Am. Rev. Respir. Dis. 143, 806-809. doi:10.1164/ajrccm/143.4_pt_1.806

Muthumalage, T., Prinz, M., Ansah, K. O., Gerloff, J., Sundar, I. K., and Rahman, I. (2017). Inflammatory and Oxidative Responses Induced by Exposure to Commonly Used E-Cigarette Flavoring Chemicals and Flavored E-Liquids without Nicotine. Front. Physiol. 8, 1130. doi:10.3389/fphys.2017.01130

Nguyen, N., McKelvey, K., and Halpern-Felsher, B. (2019). Popular Flavors Used in Alternative Tobacco Products Among Young Adults. J. Adolesc. Health 65 (2), 306-308. doi:10.1016/j.jadohealth.2019.05.004

Omaiye, E. E., McWhirter, K. J., Luo, W., Pankow, J. F., and Talbot, P. (2019a). High-Nicotine Electronic Cigarette Products: Toxicity of JUUL Fluids and Aerosols Correlates Strongly with Nicotine and Some Flavor Chemical Concentrations. Chem. Res. Toxicol. 32 (6), 1058-1069. doi:10.1021/ acs.chemrestox. $8 \mathrm{~b} 00381$

Omaiye, E. E., McWhirter, K. J., Luo, W., Tierney, P. A., Pankow, J. F., and Talbot, P. (2019b). High Concentrations of Flavor Chemicals Are Present in Electronic Cigarette Refill Fluids. Sci. Rep. 9 (1), 2468. doi:10.1038/s41598-019-39550-2

Pankow, J. F., Kim, K., McWhirter, K. J., Luo, W., Escobedo, J. O., Strongin, R. M., et al. (2017). Benzene Formation in Electronic Cigarettes. PLoS One 12 (3), e0173055. doi:10.1371/journal.pone.0173055
Pepper, J. K., Ribisl, K. M., and Brewer, N. T. (2016). Adolescents' Interest in Trying Flavoured E-Cigarettes. Tob. Control. 25 (Suppl. 2), ii62-ii66. doi:10.1136/tobaccocontrol-2016-053174

Rahman, M. M., Abd El-Aty, A. M., Choi, J.-H., Shin, H.-C., Shin, S. C., and Shim, J.-H. (2015). Basic Overview on Gas Chromatography Columns. Analytical Separation Science, 3, 823-834.

Rickard, B. P., Ho, H., Tiley, J. B., Jaspers, I., and Brouwer, K. L. R. (2021). E-cigarette Flavoring Chemicals Induce Cytotoxicity in HepG2 Cells. ACS Omega 6 (10), 6708-6713. doi:10.1021/acsomega.0c05639

Russell, C., McKeganey, N., Dickson, T., and Nides, M. (2018). Changing Patterns of First E-Cigarette Flavor Used and Current Flavors Used by 20,836 Adult Frequent E-Cigarette Users in the USA. Harm Reduct J. 15 (1), 33. doi:10.1186/ s12954-018-0238-6

Schober, W., Szendrei, K., Matzen, W., Osiander-Fuchs, H., Heitmann, D., Schettgen, T., et al. (2014). Use of Electronic Cigarettes (E-cigarettes) Impairs Indoor Air Quality and Increases FeNO Levels of E-Cigarette Consumers. Int. J. Hyg. Environ. Health 217 (6), 628-637. doi:10.1016/ j.ijheh.2013.11.003

Scientific Working Group for Forensic (2013). Scientific Working Group for Forensic Toxicology (SWGTOX) Standard Practices for Method Validation in Forensic Toxicology. J. Anal. Toxicol. 37 (7), 452-474. doi:10.1093/jat/ bkt054

Sigma-Aldrich (2013). GC Column Selection Guide. Available: https://www. sigmaaldrich.com/deepweb/assets/sigmaaldrich/marketing/global/documents/ 891/300/t407133.pdf (Accessed September 22, 2021).

Stanfill, S. B., Brown, C. R., Yan, X., Watson, C. H., and Ashley, D. L. (2006). Quantification of Flavor-Related Compounds in the Unburned Contents of Bidi and Clove Cigarettes. J. Agric. Food Chem. 54 (22), 8580-8588. doi:10.1021/ jf060733o

The_Good_Scents_Company (1980). The_Good_Scents_Company. Available: http://www.thegoodscentscompany.com/data/rw1004991.html (Accessed August 23, 2021).

Tierney, P. A., Karpinski, C. D., Brown, J. E., Luo, W., and Pankow, J. F. (2016). Flavour Chemicals in Electronic Cigarette Fluids. Tob. Control. 25 (e1), e10-e15. doi:10.1136/tobaccocontrol-2014-052175

Truman, P., Stanfill, S., Heydari, A., Silver, E., and Fowles, J. (2019). Monoamine Oxidase Inhibitory Activity of Flavoured E-Cigarette Liquids. Neurotoxicology 75, 123-128. doi:10.1016/j.neuro.2019.09.010

Vas, C. A., Porter, A., and McAdam, K. (2019). Acetoin Is a Precursor to Diacetyl in E-Cigarette Liquids. Food Chem. Toxicol. 133, 110727. doi:10.1016/ j.fct.2019.110727

Vreeke, S., Peyton, D. H., and Strongin, R. M. (2018). Triacetin Enhances Levels of Acrolein, Formaldehyde Hemiacetals, and Acetaldehyde in Electronic Cigarette Aerosols. ACS Omega 3 (7), 7165-7170. doi:10.1021/acsomega.8b00842

Zhu, S.-H., Sun, J. Y., Bonnevie, E., Cummins, S. E., Gamst, A., Yin, L., et al. (2014). Four Hundred and Sixty Brands of E-Cigarettes and Counting: Implications for Product Regulation. Tob. Control. 23 (Suppl. 3), iii3-iii9. doi:10.1136/ tobaccocontrol-2014-051670

Conflict of Interest: MG received a research grant from Pfizer and is a member of advisory board to Johnson and Johnson.

The author declares that the research was conducted in the absence of any commercial or financial relationships that could be construed as a potential conflict of interest.

Publisher's Note: All claims expressed in this article are solely those of the authors and do not necessarily represent those of their affiliated organizations, or those of the publisher, the editors and the reviewers. Any product that may be evaluated in this article, or claim that may be made by its manufacturer, is not guaranteed or endorsed by the publisher.

Copyright $\odot 2021$ Page and Goniewicz. This is an open-access article distributed under the terms of the Creative Commons Attribution License (CC BY). The use, distribution or reproduction in other forums is permitted, provided the original author(s) and the copyright owner(s) are credited and that the original publication in this journal is cited, in accordance with accepted academic practice. No use, distribution or reproduction is permitted which does not comply with these terms. 